\title{
Approximate Analytical study of unsteady Hybrid nanofluid in the presences of magnetic field with convective boundary condition over a stretching surface
}

\author{
Ali Rehman \\ Universiti Malaysia Terengganu \\ Waris khan ( $\square$ wariskhan758@yahoo.com ) \\ Hazara University
}

\section{Research Article}

Keywords: water base Hybrid Nano-fluid, MHD, stretching surface, OHAM

Posted Date: April 23rd, 2021

DOI: https://doi.org/10.21203/rs.3.rs-421383/v1

License: (c) (i) This work is licensed under a Creative Commons Attribution 4.0 International License. Read Full License 


\section{Abstract}

The objective of this researcher paper is to study the analytical solution of unsteady hybrid nanofluid in the presences of magnetic field over a stretching surface. By using similarity transformation the major partial differential equation is converted to a set of nonlinear ordinary differential equation the analytical method (OHAM) is used to find the approximate analytical solution of the nonlinear ordinary differential equation The BVPh 2.0 package function of MATHEMATICA is used to obtained the numerical results the result of important parameter such as, magnetic parameter, Prandtl number, Eckert number and surface convection parameter for both velocity and temperature profile are plotted and discuss. The BVPh 2.0 package is used to obtained the converges of the problem up to 25 iterations. The skin friction coefficient and Nusselt is explained in table form.

\section{Full Text}

This preprint is available for download as a PDF.

\section{Figures}

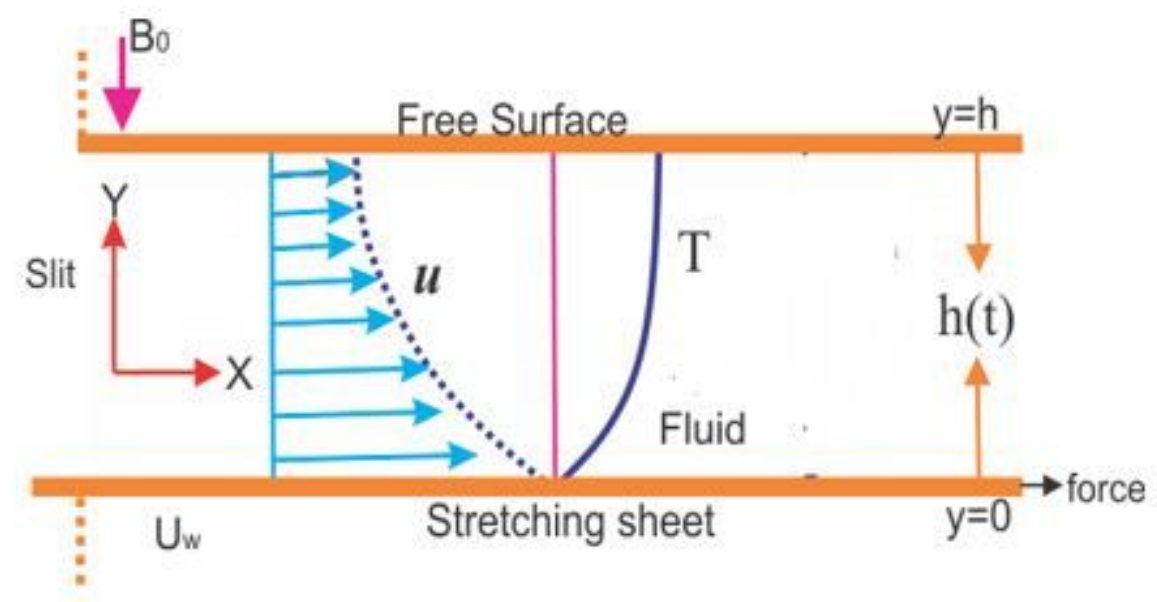

\section{Figure 1}

Geometry of the problem. 


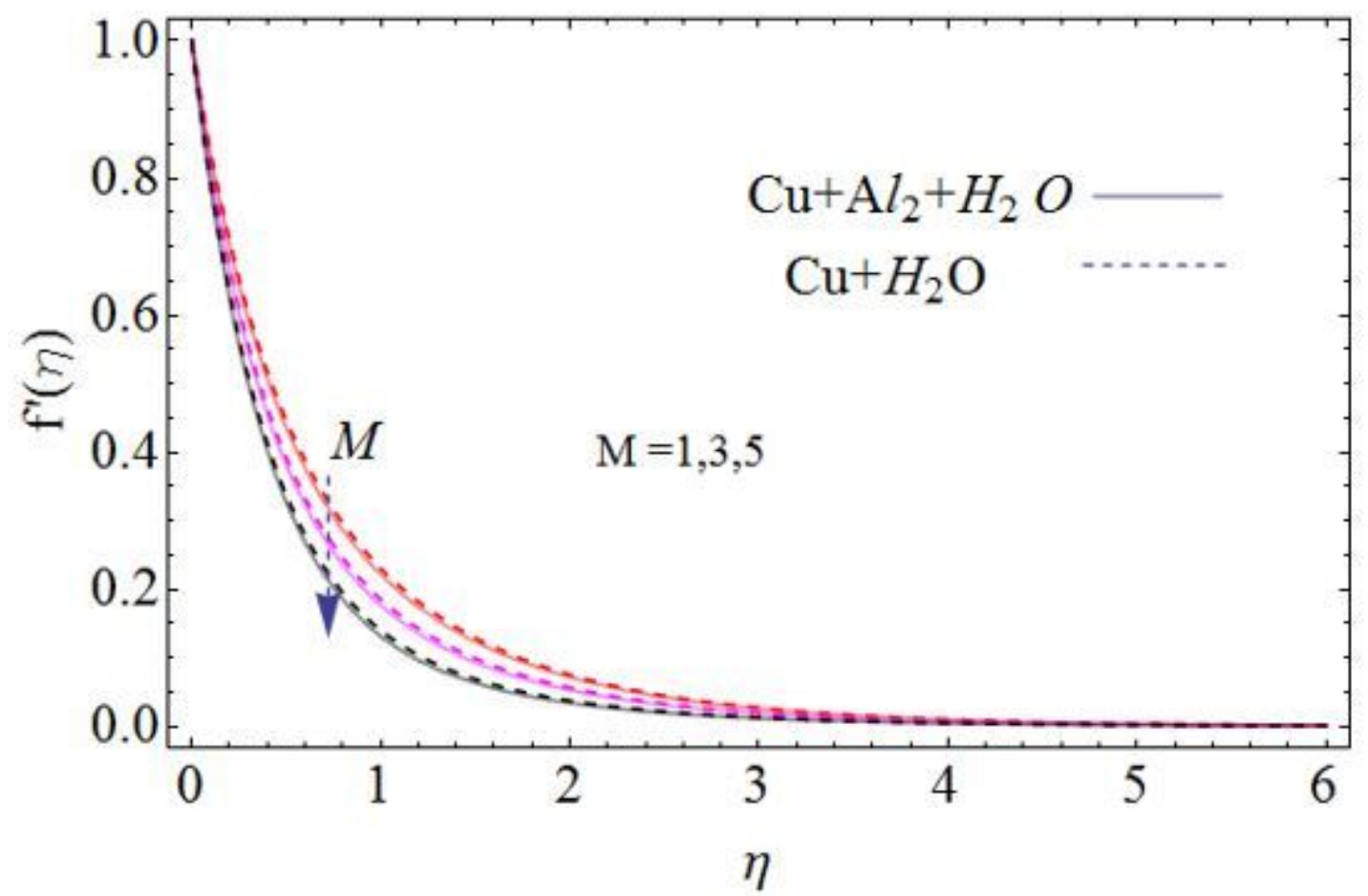

Figure 2

effect of magnetic field on velocity profile

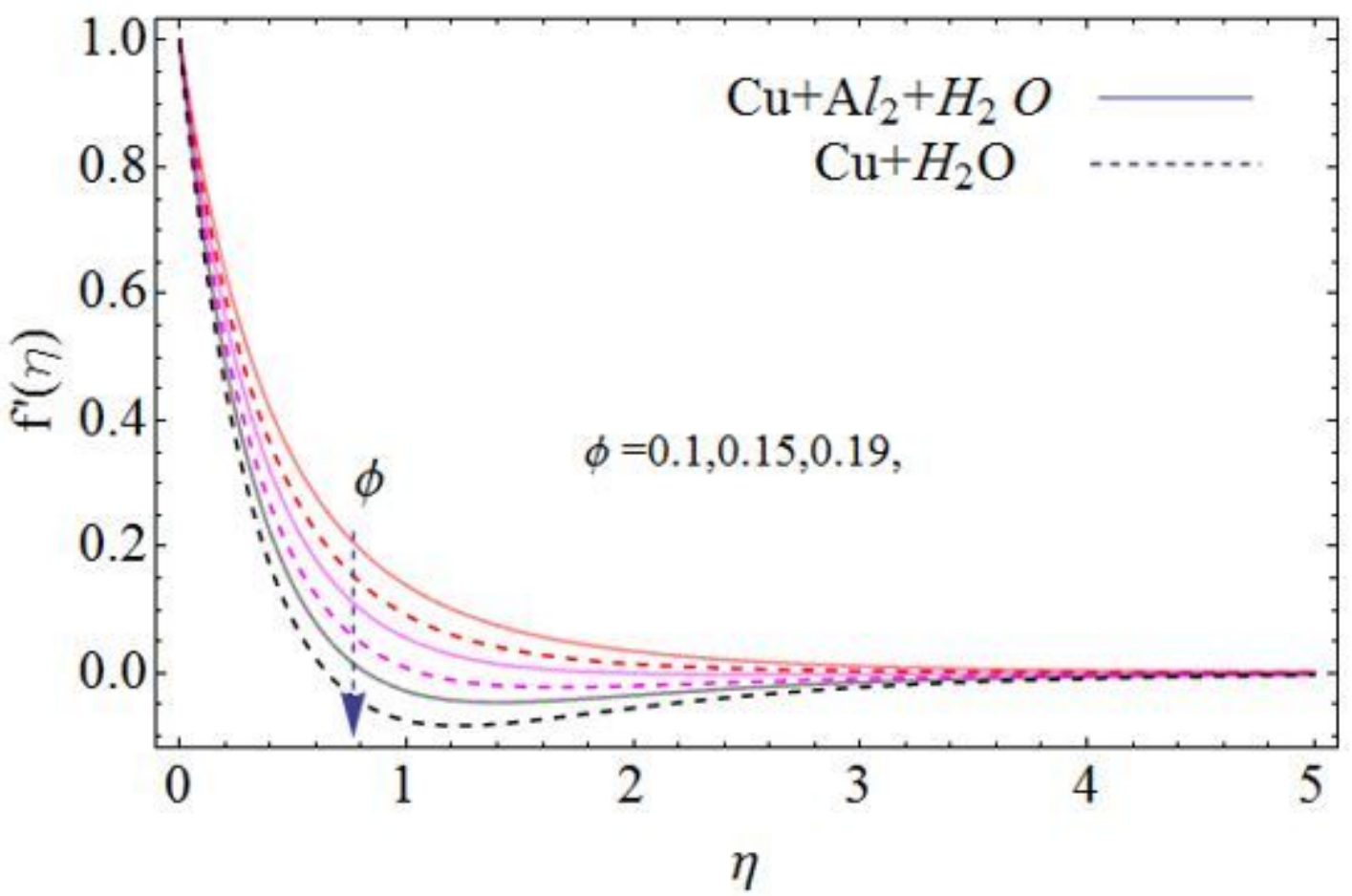

Figure 3 
effect of dimensional less nanoparticle volume fraction on velocity profile

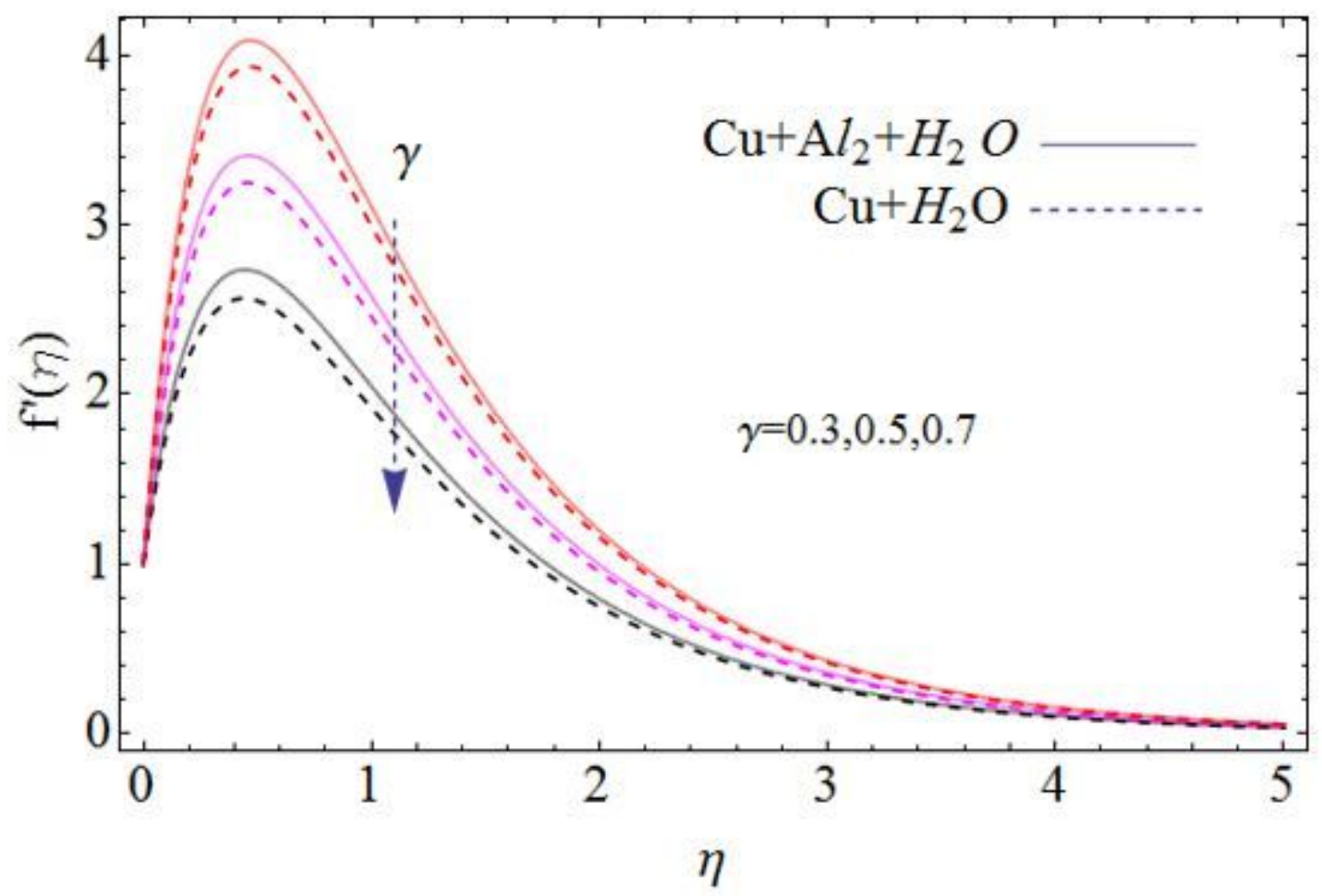

Figure 4

effect of surface convection parameter on velocity profile

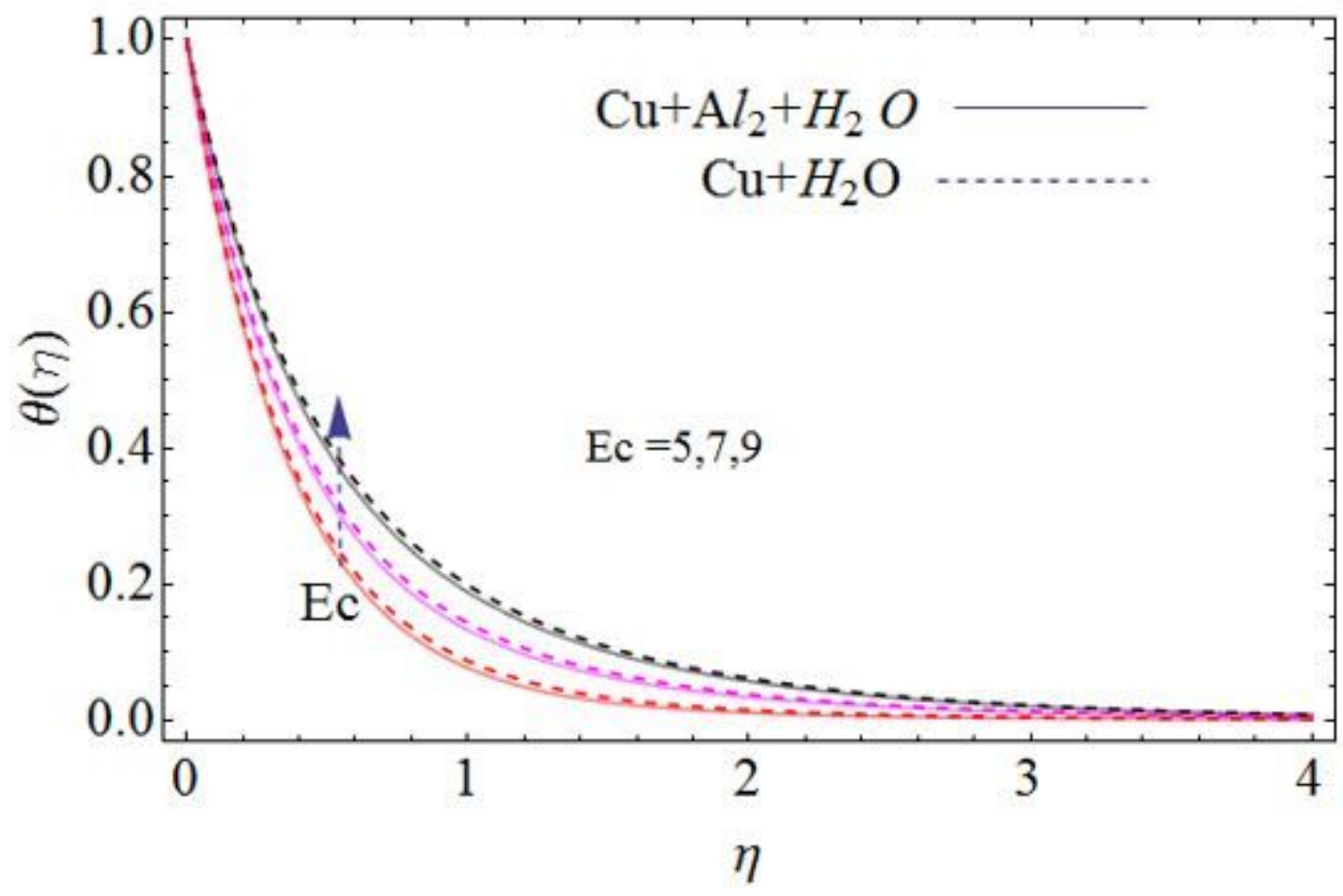


Figure 5

Effect of Eckert number on the temperature profile.

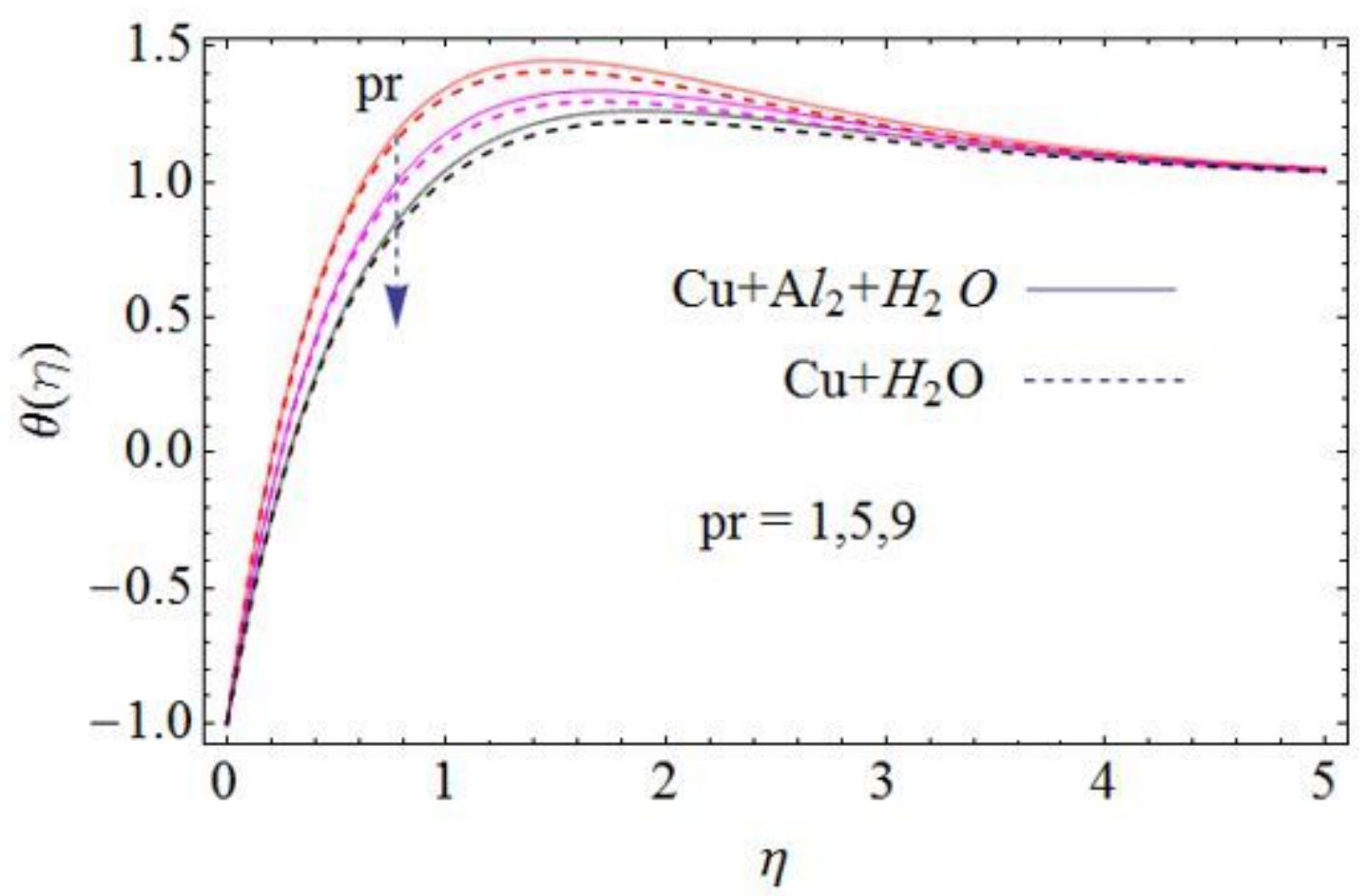

Figure 6

Effect of Prandtl number versus temperature profile

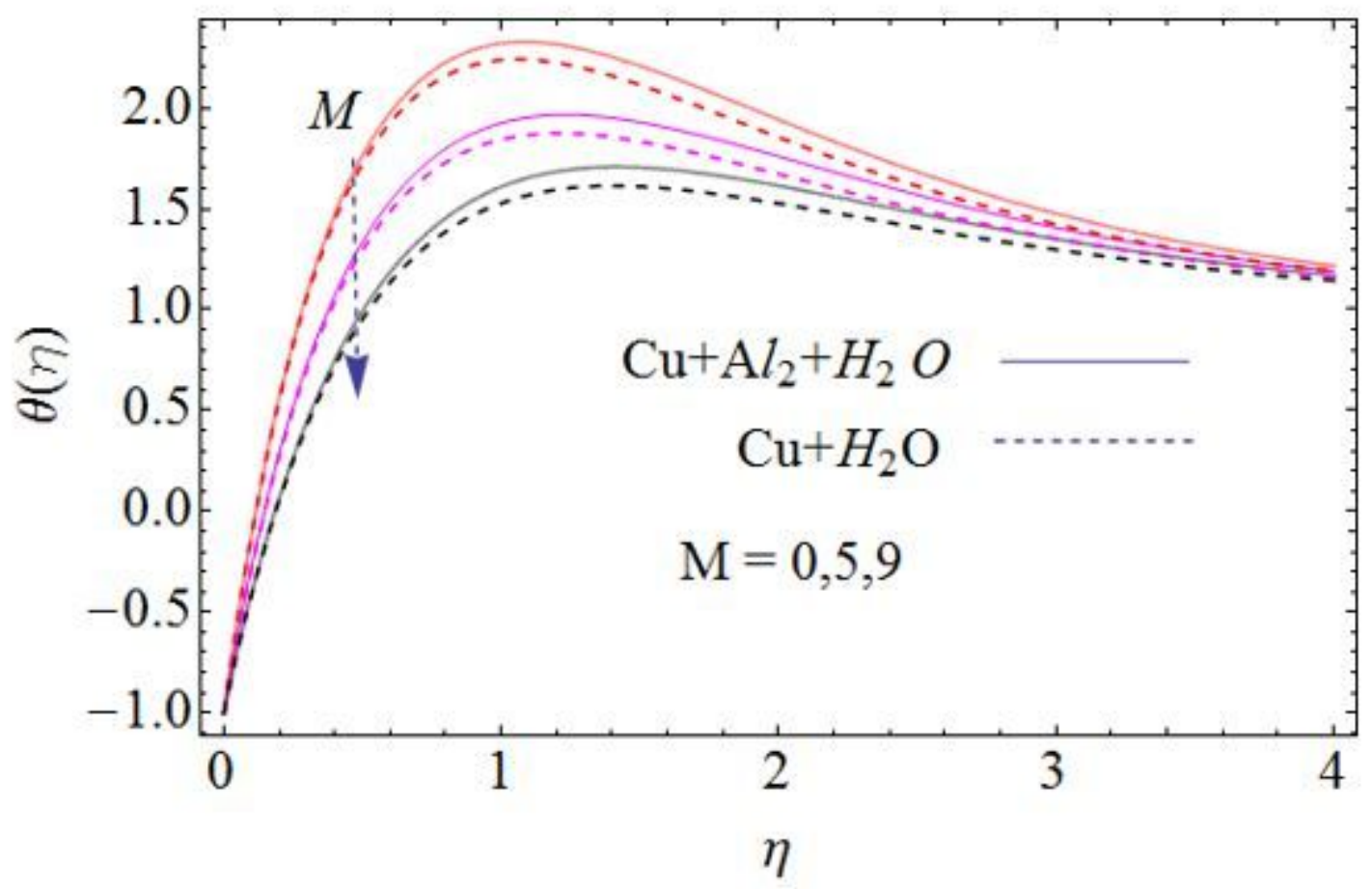


Figure 7

Effect of magnetic field versus temperature profile

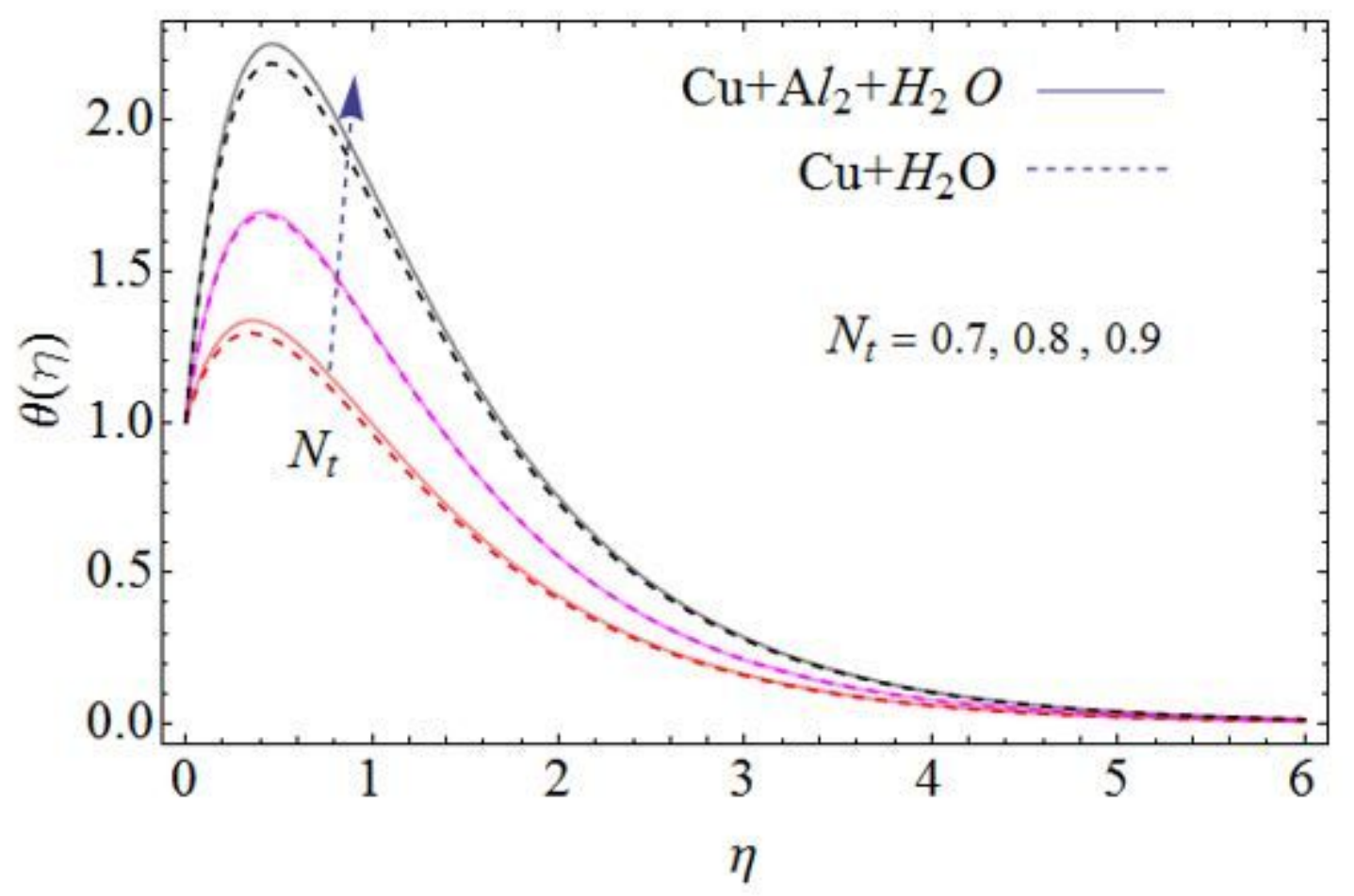

Figure 8

Effect of thermophoresis parameter versus temperature profile 